\title{
Some aspects of / $r$ / articulation in French Vocal Speech
}

Ulyana Kochetkova

Department of Philology, Saint-Petersburg State University, Russia

https://doi.org/10.36505/ExLing-2016/07/0018/000277

\begin{abstract}
This study analyses some common and individual strategies in choosing / $\mathrm{r} /$-variants in French vocal speech. The problem of the $/ \mathrm{r} /$ pronunciation is approached from a new side by considering deviations from singers' main / $\mathrm{r} /$ articulation model. The following analysis has been done: examination of the individual and common preferences of 2 different generations of singers in $/ \mathrm{r} /$ articulation in French lyric songs and operatic arias; study of deviations frequency in different phonetic contexts in its relation to musical phrase boundaries.
\end{abstract}

Key words: singing, French, phonetic-phonological analysis, pronunciation models.

\section{Introduction}

The question of the French $/ \mathrm{r} /$ articulation is today one of the most discussed subjects both due to its variety in the contemporary standard French and to the existing differences of views on pronouncing this consonant on stage in Opera as well as in Art Songs (Melodies). There is no absolute agreement among singers, singing teachers, accompanists and coaches about which variant is preferable: the "Italianate" apical alveolar trill or flap suggested from $17^{\text {th }}$ century onward as the only correct pronunciation in singing (Bacilly 1679, Garcia 1851, Duval 1878, Lavoix, Lemaire 1881, Grubb 1979, Yarbrough 1991); or the conversational uvular consonant, the latter having been criticized for its "vulgarity" and destroying effect that it produces on surrounding vowels and airflow projection in general (Nedecky 2015) or recommended only to French native singers (Vennard 1967). However, the uvular consonant is consistently observed not only in some famous modern French singers' performances (Nedecky 2015),but can also be found (though seldom) even in the interpretations by renowned artists of the past, who themselves crucially criticized it.

Today most of non-French contemporary singers face certain problems and difficulties when performing an opera or lyric song written by a French composer, for it is one of the most complicated languages for a non-native speaker to sing. The modern performing art standards

ExLing 2016: Proceedings of $7^{\text {th }}$ Tutorial and Research Workshop on Experimental Linguistics, 27 June - 2 July 2016, Saint Petersburg, Russia 
are high, but there is a lack of panoramic theoretical and experimental works in this field, so that the current study will be a contribution to it.

\section{Methods and material}

At the first stage, in order to provide data for the identification of the preferences in $/ \mathrm{r} /$ articulation by contemporary French singers in comparison with their previous centuries colleagues, 87 French lyric songs, 36 operatic arias and 3 whole operas in stage production were analysed. The material includes recordings of 25 French singers (12 male and 13 female voices), who can be divided in 2 groups: 14 singers born after 1950 and 11 singers born before 1950. However the above mentioned works were not interpreted by every of the 25 singers, because the diversity and the heterogeneity of the material caused a range of problems: 1) some old recordings have a quality which is not sufficient for the appropriate analysis; 2) several recent live or broadcast recordings may contain some noise; 3) the repertoire of different singers is specific and restricted to a concrete style of music, depending on the singer's voice and background.

The singer's preferred model in two different genres (Opera vs. Art Songs), as well as in two different styles (French Lyric Opera vs. French Baroque Opera) was established in the following way: singers were evaluated as $[\mathrm{B}]$ or $[\mathrm{r}]$ preferring, if they used a certain model in more than $50 \%$ of analysed works.

Although the use of the uvular [B] is commonly regarded as a recent trend, it was observed that 5 contemporary singers choose alveolar $[\mathrm{r}]$ in both styles and both genres, and 3 other contemporary singers of the same group performed baroque opera using only the alveolar variant of $/ \mathrm{r} /$, even though they articulate often or mostly the uvular consonant in the Romantic opera. On the other hand performances of the previous generations of singers contained the uvular consonant (even in Baroque music). It allowed us to suppose that the Baroque educational background developing leads to a more elaborate and conscious way of working on the articulatory aspect.

At the second stage of this study the relation of phonetic contexts with the deviations from the singer's preferred model was examined in 58 Art Songs, in which at least one deviation occurred (songs with no deviations, as well as operatic arias were excluded from the material in order to avoid other factors' potential impact).From 1 to 10 interpretations of each piece were considered. This part of material included performances of ten contemporary and ten early $20^{\text {th }}$ century singers; five of them preferred $[\mathrm{b}]$-model (only contemporary performers), fifteen singers preferred $[\mathrm{r}]$-model. 


\section{Results}

In the studied material 15 different types of phonetic contexts were defined, presenting 5 main groups: 1) intervocalic - VRV ("horizons"); 2) musical phrase initial position - RV ("reviens"), RCV ("roi"), CRV ("cri"), CRCV ("trois"); 3) final position before breath pause - VR ("Lahor"); 4) pre- or postconsonantal before or after 1 consonant - VRC ("courtes"), VCRV ("tendre"), VRCV ("en ruines"); 5) interconsonantal in different types of clusters - VCCRV ("ellecrie"), VRCCV ("lorsque") including clusters with semivowels - VCRCV ("endroit"), VCCRCV ("ellecroit") or another "r" - VRRV ("coeurregrette"), VRCRV ("arbre"). Total amount of contexts with / $\mathrm{r} /$ in the analysed vocal texts was 1814. The following types of phonetic contexts were the most frequent ones: "VRV" (34\%), "VRC" (32\%), "VCRV" (19\%).

Deviations from different $/ \mathrm{r} /$ articulation models were considered separately for singers preferring alveolar articulation and for those preferring the uvular one. In order to normalize data, deviation in each concrete context was counted as 1, if it occurred at least in one singer's interpretation. Then, the percentage of the deviations in each type of phonetic context to the total amount of these phonetic contexts in the material was obtained.

Figure 1 represents the normalized frequency of the deviations from the individual's main alveolar $[\mathrm{r}]$ articulation model in different types of phonetic contexts. Deviations occurred more frequently in the following phonetic contexts: before breath pause (VR, 27\%), in the consonant cluster with another / $\mathrm{r} /(\mathrm{VRCRV}, 26 \%$ ), in intervocalic position (VRV, $23 \%$ ), in the initial position in musical phrase after one consonant (CRV, $20 \%$ ). Frequency of other types of contexts is less than $20 \%$.

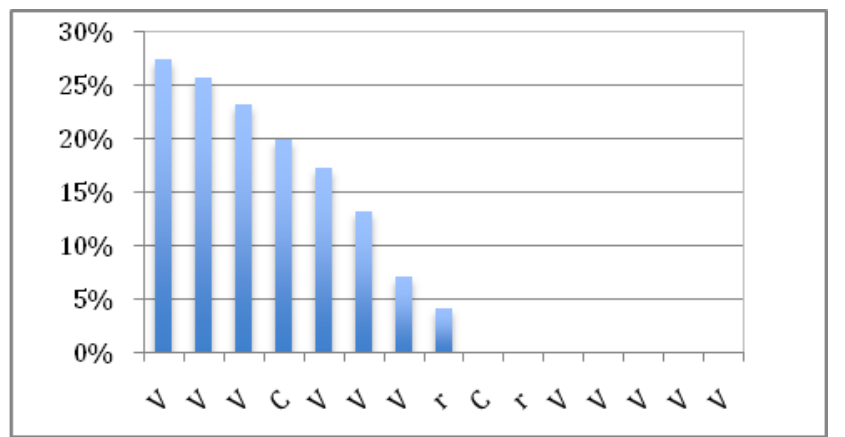

Figure 1. Frequency of deviations from $[\mathrm{r}]$-model in different types of phonetic contexts. 
As it was mentioned above, at this stage of analysis the French uvular consonant was observed as the main / $\mathrm{r} /$-articulation model only for 5 singers in the studied material (see table 1); four of them had deviations in their performances. As long as deviations from the uvular articulation occurred only in 27 cases, it is impossible to make a reliable comparison with the results obtained for $[\mathrm{r}]$-model. But it is an interesting fact that the deviations from $[\mathrm{b}]$-articulation model occurred in the contexts, which were considered as favorable for the deviations from the model with the alveolar consonant.

Table 1. Number of deviations from [b]-model in different types of phonetic contexts.

\begin{tabular}{|l|l|l|l|l|l|}
\hline \hline Phonetic contexts & Singer1 & Singer 2 & Singer 3 & Singer 4 & $\begin{array}{l}\text { Total } \\
\text { number }\end{array}$ \\
\hline VR & 1 & 2 & 0 & 0 & 3 \\
\hline VRC & 5 & 7 & 0 & 2 & 14 \\
\hline VRV & 0 & 5 & 1 & 0 & 6 \\
\hline VCRV & 0 & 2 & 0 & 0 & 2 \\
\hline VRCRV & 0 & 0 & 0 & 2 & 2 \\
\hline
\end{tabular}

\section{Conclusion}

This study allowed to make the following observations: 1) different $/ \mathrm{r} /$ articulation preferences in singing exist in both singers' age groups; 2) deviations from two different models are possible in both groups; 3) some contemporary performers never choose the model with the uvular consonant (even in lyric songs); 4) some of the contemporary singers use different $/ \mathrm{r} /$-articulation main models in different styles (Romantic vs. Baroque); 5) some phonetic contexts, as well as the initial or final position in a musical phrase may influence the occurrence of deviations from the chosen / $\mathrm{r} /$-articulation model.

\section{References}

Bacilly, B (de). 1679. L'art de bien chanter de M.de Bacilly. Paris, Bacilly.

Garcia, M. 1851.Ecole de Garcia: traité complet de l'art du chant. Paris, Mayence.

Grubb, Th. 1979. Singing in French: a Manual of French Diction and French Vocal Repertoire. Belmont, Schirmer Books.

Duval, G. 1878. Artistes etcabotins. Paris, Ollendorf.

Lavoix, H., Lemaire, Th. 1881. Le chant. Sesprincipeset son histoire. Paris, Heugeletfils. Nedecky, J. 2015. French Diction for Singers. A Handbook of Pronunciation for French Opera and Melodie. Toronto, Book POD.

Vennard, W. 1967. Singing. The Mecanism and the Technic. New York, Karl Fischer. Yarbrough, J. 1991. Modern Languages for Musicians. Stuyvesan, Pendragon Press. 